\title{
Precipitation delivery trajectories associated with extreme river flow for the Waitaki River, New Zealand
}

\author{
D. G. Kingston and J. McMecking \\ Department of Geography, University of Otago, Dunedin, New Zealand \\ Correspondence to: D. G. Kingston (daniel.kingston@otago.ac.nz)
}

Received: 15 April 2015 - Accepted: 15 April 2015 - Published: 11 June 2015

\begin{abstract}
Analysis of large-scale climate conditions associated with extreme river flow is an important first step in the development of predictive relationships for such events. The potential of this approach is demonstrated here for the Waitaki River (a river of national importance in terms of electricity generation), in the Southern Alps of New Zealand. Here, atmospheric circulation anomalies and air parcel trajectories associated with such events are investigated for the period 1960-2010, using the NCEP/NCAR reanalysis and HYSPLIT trajectory model. Results show that atmospheric circulation variation and air parcel trajectories associated with extreme high Waitaki river flow events typically follow two distinct patterns. These patterns are associated with differences in both New Zealand- and hemispheric-scale atmospheric circulation, but all occur under a similar pattern of monthly average pressure anomalies. As such, the results indicate that different precipitation generation mechanisms are captured by a single monthly climate anomaly pattern - providing substantial new understanding of the cascade of processes linking atmospheric to surface hydrological variation in the Southern Alps, and pointing the direction for future process-informed research on sources of predictability for Waitaki river flow.
\end{abstract}

\section{Introduction}

Analysis of the immediate large-scale climate drivers of extreme high river flow is an important first step in the development of predictive relationships for such events. Prediction of river flow is a particularly important research goal from an applied perspective when river water is used for electricity generation, as is the case for the Waitaki River in New Zealand (the seven power stations on this river comprise $17 \%$ of national electricity generation; Electricity Authority, 2011). As well as causing potentially damaging floods, extreme river flow is challenging from a management perspective, and potentially costly (water spilled from dams cannot be used for electricity generation).

The position of New Zealand in the mid-latitude of the southern hemisphere results in a strong link between the climate of New Zealand and the general southern hemisphere atmospheric circulation. In particular, the climate of New Zealand is influenced by both the Southern Annular Mode and the Southern Oscillation (Gordon, 1986; Kidston et al., 2009). At the same time, the presence of a substantial topographic barrier (the Southern Alps; peaks $>3000 \mathrm{~m}$ ) orien- tated near-perpendicular to the prevailing westerly circulation results in strong climatic variation over short distances, resulting in a complex combination of large and small scale influences on the climate across the South Island.

It has been demonstrated previously that weak-tomoderate relationships exist between the SO and Waitaki river flow on a lagged seasonal basis (e.g. McKerchar et al., 1998). Predictive relationships of similar strength for the Waitaki have also been found between geopotential height and SST at a series of locations near to and far from New Zealand (Purdie and Bardsley, 2010). In terms of concurrent atmosphere-river flow relationships, it has been shown that a series of circulation indices that describe the meridional and zonal components of atmospheric circulation over New Zealand (and along the axis of the Southern Alps in particular: the MZ1 and MZ2) have a strong relationship to Pukaki inflow (correlation coefficients $>0.7$; Kingston et al., 2014).

Despite the occurrence of atmosphere-river flow relationships at the monthly timescale, the atmospheric processes that cause individual extreme events can only be inferred from statistical relationships at this temporal resolution. In- 
deed, such time-averaged relationships may mask some atmospheric variation associated with extremes of discharge, thus limiting their usefulness as a basis for understanding the causes (and so predictability) of such events. In response to this research gap, here the applicability of previously identified relationships at the monthly timescale (Kingston et al., 2014) to daily and event-scale flow extremes is investigated for the Waitaki river, focussing specifically on inflow to Lake Pukaki (an important headwater lake of the Waitaki). There are two steps to this analysis: firstly, investigation of daily geopotential height fields associated with extreme high river flow events, and secondly, of precipitation delivery mechanisms for specific extreme flow events (identified using backtrajectory analysis). The situation of the trajectories within the daily circulation anomalies is also analysed, together with a comparison against previously described monthlyresolution relationships (Kingston et al., 2014). The resultant improved understanding of the cascade of processes linking atmospheric to extreme surface hydrological variation will ultimately inform further development of lag-lead relationships for prediction of extremes and river flow more generally.

\section{Data and methods}

The Waitaki river $\left(11900 \mathrm{~km}^{2}\right)$ drains from the Southern Alps in an approximate southeasterly direction towards the east coast of the South Island. Lake Pukaki $\left(1457 \mathrm{~km}^{2}\right)$ is the largest headwater lake of the Waitaki, and together with Lakes Tekapo and Ohau is responsible for the majority of the downstream variation in river flow (inflow to all three lakes are highly correlated). Lake Pukaki is located in an alpine environment, and in consequence an important fraction of precipitation falls as snow, particularly during the winter halfyear (April-October). The highest inflow to the lake occurs during summer, with annual low flows during winter. On a seasonal basis the majority of inflows are derived from seasonal snow and ice melt, but with rainfall (or rain-on-snow) generally causing the highest individual inflow events (McGowan and Sturman, 1996).

Climate within the upper Waitaki basin follows a strong gradient, from high alpine (Aoraki/Mount Cook, $3724 \mathrm{~m}$ ) through to the inter-montane Mackenzie valley (approx. $500 \mathrm{~m}$ ) in which Lake Pukaki terminates. Mean annual precipitation in the headwaters has been estimated at $15000 \mathrm{~mm}$, falling to approximately $700 \mathrm{~mm}$ near the terminus of the lake (Kerr et al., 2011).

Daily lake inflow records are available for Lake Pukaki from the 1920s to the present day, and were obtained from Meridian Energy (the current operator of the hydroelectricity scheme for this lake). Daily precipitation data were sourced from the Hermitage/Mt Cook weather station near the head of Lake Pukaki (altitude $730 \mathrm{~m}$ ), and used to confirm that inflow events were associated with a substantial rainfall event.

Previous research (Kingston et al., 2014) has identified September-December as the time of year with strongest linkages to atmospheric circulation patterns in the broader New Zealand region, so inflow records from these months were the focus here. The top 10 daily inflow events for each month (i.e. the top 10 September events, the top 10 October events, and so on) were identified. A month-by-month approach was used to avoid complications associated with the seasonal cycle.

The atmospheric drivers of the high inflow events were examined in two stages. Firstly, daily geopotential height fields at the time of high inflow events were analysed, using NCEP/NCAR reanalysis data (Kalnay et al., 1996). Geopotential height fields at $1000 \mathrm{hPa}$ were examined initially to determine the extent to which daily atmospheric circulation patterns in the New Zealand region corresponded to the monthly relationships identified previously (Kingston et al., 2014). Additionally, larger-scale atmospheric circulation features during high inflow events were examined via $700 \mathrm{hPa}$ geopotential heights across the extratropical southern hemisphere, to determine the connection between New Zealand regional circulation and more general features of the southern hemisphere atmosphere. Following previous identification of these indices as good descriptors of Waitaki lake inflow, the MZ1 and MZ2 were calculated on a daily time-step (following the procedure outlined by Salinger and Mullan (1999) for calculation of these indices with monthly data) to investigate whether extreme inflow events corresponded with extreme daily values of these indices. These indices describe the pressure gradient anomaly between Gisborne and Hokitika (MZ1) and Gisborne and Invercargill (MZ2). The availability of data from these locations resulted in these indices being calculated for the period 1960 to 2010 - in consequence this formed the period of analysis.

The second stage of the analysis involved determining the backwards trajectory of the air parcel over the approximate location of Lake Pukaki at the time of the high inflow event, and so provides further detail of the processes involved in delivering precipitation to the Pukaki catchment above that provided by daily circulation anomalies. Backtrajectory analysis was performed using the NOAA HYSPLIT tool (Draxler and Rolph, 2014), using NCEP/NCAR reanalysis data. Owing to uncertainty as to the exact timing during the day of peak inflow and peak precipitation, a series of trajectories were plotted for each event to ensure that the atmospheric drivers were captured. For each event, trajectories were started at four hour intervals, going backwards from midnight at the end of the day of the inflow peak, with six trajectories calculated in total. Trajectory duration was $72 \mathrm{~h}$; an iterative process was followed to determine the most informative duration.

Trajectories were examined at sea level (rather than at a higher level in the atmosphere) because a critical process 

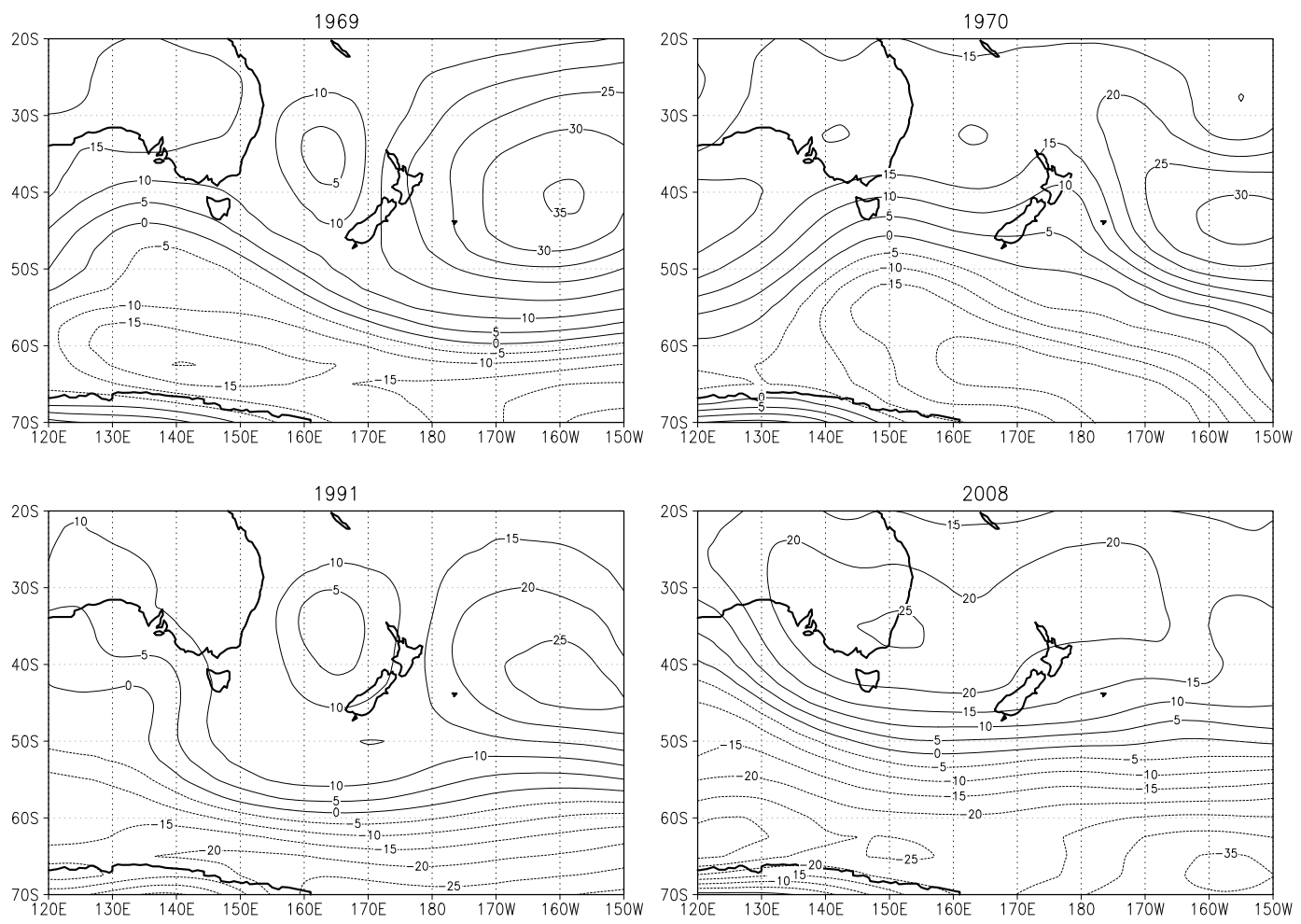

Figure 1. $1000 \mathrm{hPa}$ geopotential height fields for the top four September inflow events (9 September 1969, 17 September 1970,13 September 1991 and 24 September 2008).

for extreme precipitation occurrence in this location is orographic uplift of moist airmasses originating from the Tasman Sea (i.e. immediately northwest of the catchment). As a result of the altitude of the Southern Alps, the moisture content of the air at sea level can be an important indicator of the likelihood of precipitation occurrence at the Main Divide. As such, even though representation of the Southern Alps is limited given the $2.5^{\circ}$ spatial resolution of the NCEP/NCAR reanalysis, occurrence of very moist air immediately upwind of Pukaki is still a very strong indicator of orographic precipitation. Given the importance of moisture content of the air, the relative humidity along the trajectory was also examined.

\section{Results}

Geopotential height fields and back-trajectories associated with extreme high inflow events can be divided into two general categories: the top four September events neatly illustrate this division (Figs. 1-3). The first category involves a pattern of high geopotential height (indicating an anticyclone) immediately to the east of New Zealand, and low geopotential height (i.e. a depression) to the west, as exemplified by the 1969 and 1991 September events (Fig. 1). Such a situation typically results in a strong pressure gradient along a SW-NE axis across New Zealand, and is reflected in strongly positive MZ1 and MZ2 index values. Analysis of
Southern Hemisphere-scale geopotential height at $700 \mathrm{hPa}$ indicates that the main band of midlatitude westerlies lie some distance south of New Zealand during these events (Fig. 2). Trajectory analysis provides further detail about the nature of atmospheric circulation upwind of Pukaki during these extreme high inflow events (Fig. 3). The trajectories come from an approximate due north direction, up to a latitude of approximately $30-35^{\circ} \mathrm{S}$, before which a westward direction of travel is evident. The air is typically reaches (or comes close to) saturation 6 to $12 \mathrm{~h}$ ahead of reaching Lake Pukaki. The position of the trajectory is relatively stable throughout the period of trajectory analysis.

The second general pattern of atmospheric circulation associated with extreme high inflow indicates a much stronger zonal circulation over New Zealand (and the South Island in particular) than for the first pattern, and is exemplified here by the September 1970 and 2008 events (Fig. 1). A trough of low pressure over New Zealand is typically present, but not a fully formed depression as evident for the first pattern. The $700 \mathrm{hPa}$ geopotential height fields show that the increased zonal circulation over New Zealand occurs because the main band of westerly winds is relatively far north (in comparison to the first group; Fig. 2). The strong pressure gradient associated with these mid-latitude westerlies results in strongly positive MZ1 and MZ2 index values. The trajectories for this second group indicate that air comes initially from a more 

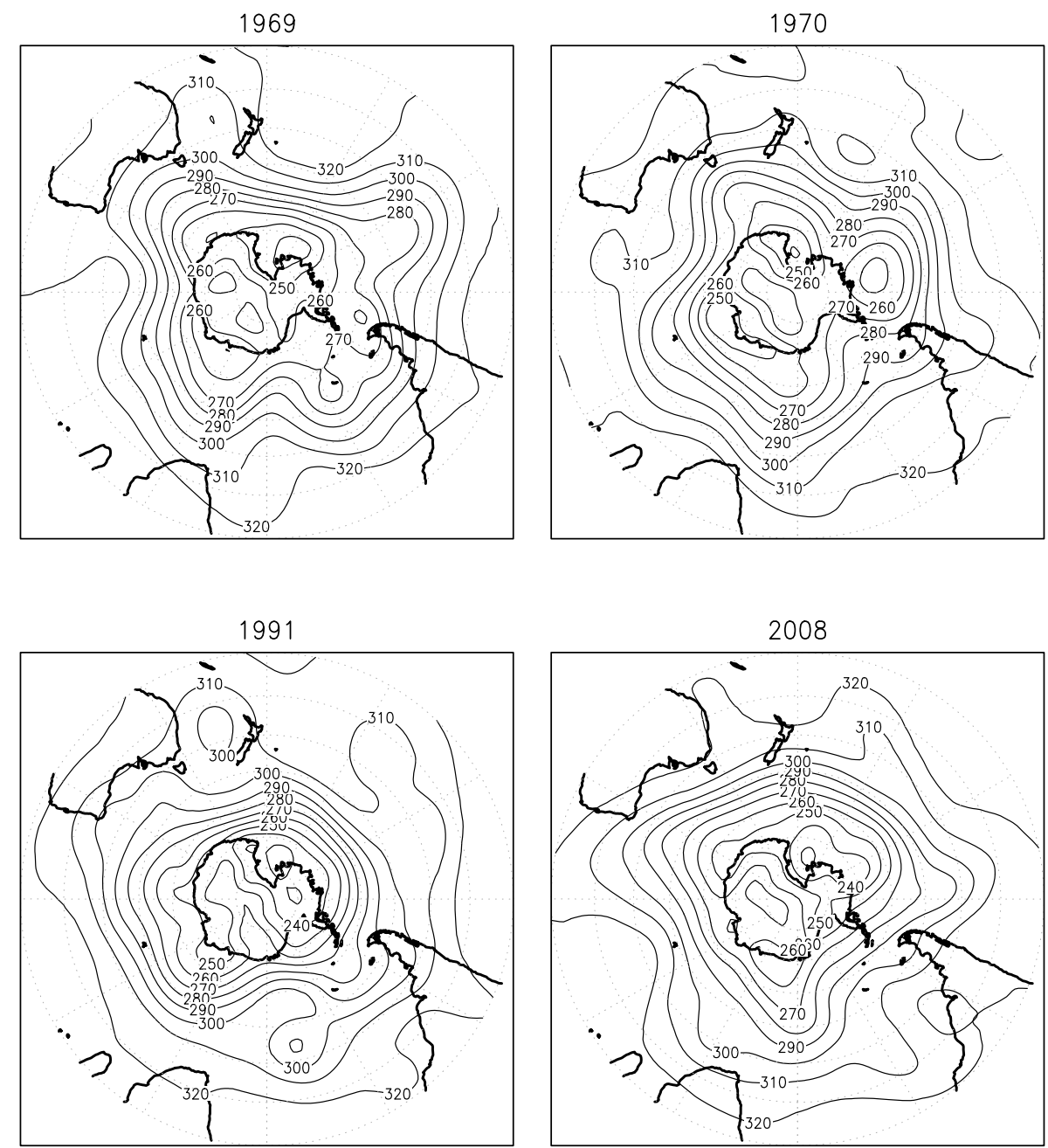

Figure 2. $700 \mathrm{hPa}$ geopotential height fields for the top four September inflow events (dates are the same as Fig. 1).

north-northwesterly direction (i.e. across the Tasman Sea) in comparison to the first pattern (Fig. 3). This flow direction occurs only for the earliest few trajectory runs, after which a more westerly trajectory is followed. The westerly orientated trajectories cover a relatively large distance over the $72 \mathrm{~h}$ period of analysis in comparison to the earlier northwesterly trajectories (and the northerly trajectories of the first pattern). The north-northwesterly trajectories are typically very humid (relative humidity $>90 \%$ is reached 6-12h upwind of Pukaki), whereas the subsequent westerly trajectories are typically below $80 \%$ relative humidity.

\section{Discussion and conclusions}

Results indicate two general patterns of atmospheric circulation (and so precipitation delivery) associated with extreme high inflow events for Lake Pukaki. The first pattern involves a pair of relatively slow moving weather systems over New Zealand: a departing anticyclone to the east, and an arriving depression to the west. Trajectory analysis suggests that in this situation Lake Pukaki is under the influence of warm, moist air (i.e. the warm "conveyor belt") in advance of an arriving cold front; conditions often associated with heavy rainfall over the Southern Alps (Brenstrum, 1998). The consistency of the location of the trajectory indicates a relatively slow moving weather system, further strengthening the likelihood of high precipitation. Trajectories for these events typically approach or reach saturation at least one time-step (i.e. six hours) upwind of Pukaki. This level of humidity indicates that rainfall is likely to already be occurring as the air mass reaches the west coast of New Zealand. This is important because it has been shown previously that the heaviest precipitation events over the Southern Alps generally occur when orographic effects enhance existing synopticoriginating precipitation (Purdy and Austin, 2003).

As with the first pattern, the second group of geopotential height and trajectory patterns indicates a warm moist air arriving from the north associated with extreme inflow, again 


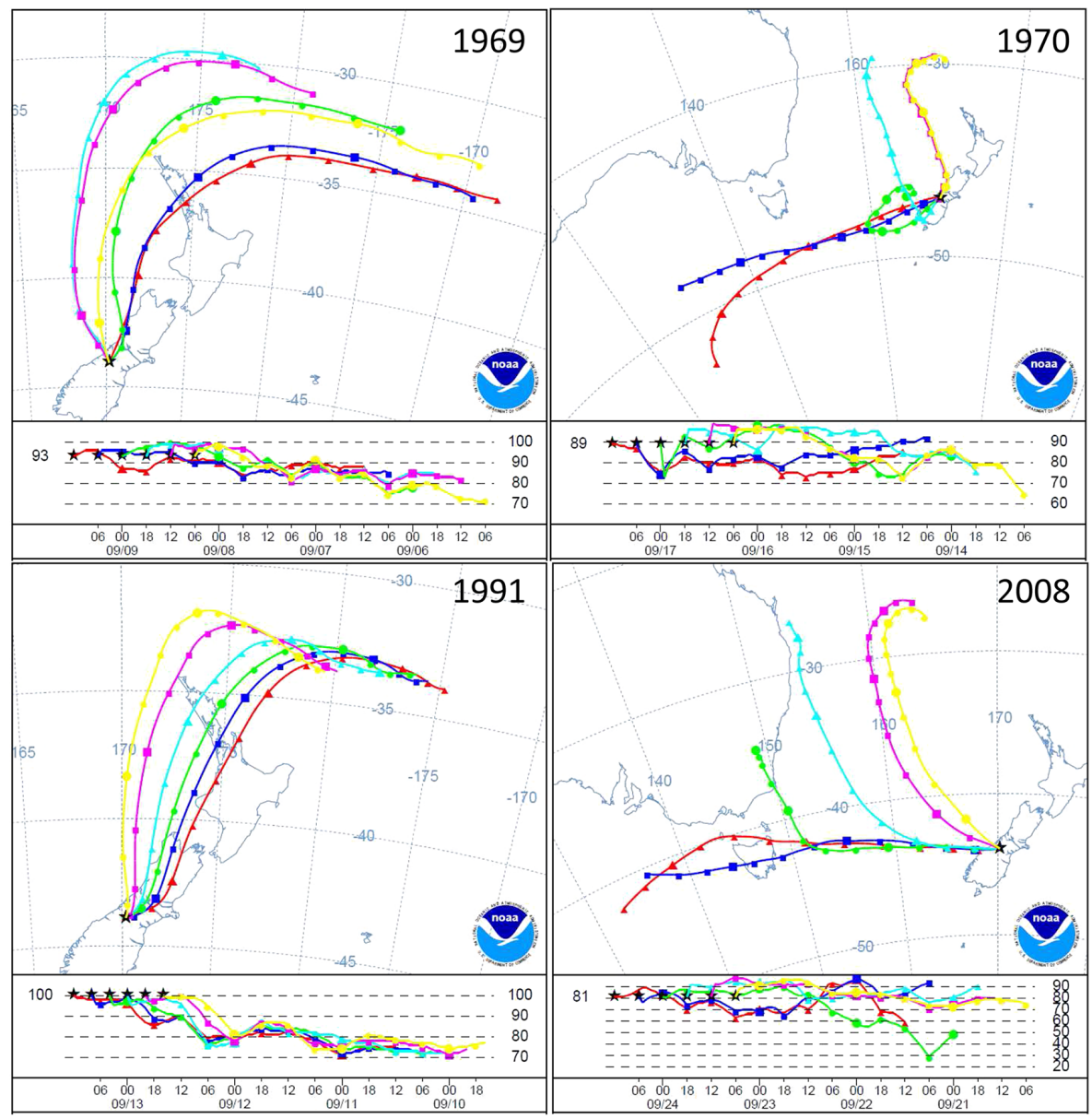

Figure 3. $72 \mathrm{~h}$ trajectories for the top four September inflow events (dates are the same as Fig. 1). The red line indicates the trajectory started at midnight at the end of the day of each event; the five further trajectories were started at four-hour intervals preceding this (with the earliest trajectory indicated by the yellow line). For each year, the upper section indicates the path of the trajectory and the lower section indicates the relative humidity $(\%)$ from the start of the trajectory.

with relative humidity close to or at $100 \%$ prior to reaching Lake Pukaki. However, pattern two differs in that the arrival of this warm moist air occurs in a much more dynamic westerly circulation, with precipitation associated with fronts embedded in a trough rather than fully formed low pressure system (as was the case for the first group). In this instance, the passage of the front and resultant change in air mass humidity are clearly visible: relative humidity changes from $>90 \%$ to below $80 \%$, the direction changes from northwesterly to westerly, and the wind speed increases substantially.

Analysis of daily MZ1 and MZ2 index values indicates that strong positive association between these indices and monthly-resolution Pukaki inflow (identified previously by Kingston et al., 2014) is also present at the daily timescale. Notwithstanding the two patterns of atmospheric circulation associated with extreme lake inflow, the consistent association with the MZ1 and MZ2 can be explained by analysis of daily geopotential height fields. For the first group, the gradient between the westward low pressure and eastward high pressure creates the southwest-northeast gradient required for extreme MZ1 and MZ2 values. For the second group, the position of the main band of westerlies close to the South Island results in a strong pressure gradient between the two sets of MZ index stations. As such, the results indicate that two different synoptic situations can result in extreme MZ1 and MZ2 index values. Perhaps more importantly, the results also demonstrate that two different precipitation generation mechanisms are captured here by a single pressure index and by a single monthly climate anomaly pattern. This finding points to the reason why the MZ1 and MZ2 are so successful in describing variation in Waitaki inflow (as previously shown by Kingston et al., 2014), and provide a critical advance in ongoing research into process-informed predictive relationships for the Waitaki. More generally, these results also demonstrate the important additional understanding that can be generated by looking in more detail beyond apparently straightforward monthly resolution relationships. 
Acknowledgements. Conversations with Erick Brenstrum, Peter Kreft and Neil Gordon (MetService, New Zealand) helped greatly with interpretation of the results. Jane McMecking was supported by a University of Otago Department of Geography summer scholarship. The authors gratefully acknowledge the NOAA Air Resources Laboratory (ARL) for the provision of the HYSPLIT transport and dispersion model and READY website (http: //www.ready.noaa.gov) used in this publication.

\section{References}

Brenstrum, E.: The New Zealand weather book, Craig Potton Publishing, New Zealand, 138 pp., 1998

Draxler, R. R., and Rolph, G. D.: HYSPLIT (HYbrid Single-Particle Lagrangian Integrated Trajectory), Model access via NOAA ARL READY Website: http://www.arl.noaa.gov/HYSPLIT.php (last access: 20 April 2015), NOAA Air Resources Laboratory, College Park, MD, USA, 2014.

Electricity Authority.: Electricity in New Zealand, Electricity Authority/Te Mana Hiko, Wellington, New Zealand, 2011.

Gordon, N. D.: The Southern Oscillation and New Zealand Weather, Mon. Weather Rev., 114, 371-387, 1986.

Kalnay, E., Kanamitsu, M., Kistler, R., Collins, W., Deaven, D., Gandin, L., Iredell, M., Saha, S., White, G., Woollen, J., Zhu, Y., Chelliah, M., Ebisuzaki, W., Higgins, W., Janowiak, J., Mo, K. C., Ropelewski, C., Wang, J., Leetmaa, A., Reynolds, R., Jenne, R., and Joeseph, D.: The NCEP/NCAR 40-year reanalysis project, B. Am. Meteorol. Soc., 77, 437-471, 1996.
Kerr, T., Owens, I. F., and Henderson, R. D.: The precipitation distribution of the Lake Pukaki Catchment, J. Hydrol., 50, 361-382, 2011.

Kidston, J., Renwick, J. A., and McGregor, J.: Hemispheric-scale seasonality of the Southern Annular Mode and impacts on the climate of New Zealand, J. Climate, 22, 4759-4770, 2009.

Kingston, D. G., Webster, C. S., and Sirguey. P.: Large-scale climate control on lake inflow in the Waitaki basin, New Zealand, Hydrology in a Changing World: Environmental and Human Dimensions, IAHS Publ. 363, Proceedings of FRIENDWater 2014, Montpellier, France, 138-144, 2014.

McGowan, H. A. and Sturman, A. P.: On the application of hydrometeorological techniques to the forecasting of inflows into alpine hydro-lakes, Phys. Geogr., 17, 513-533, 1996.

McKerchar, A. I., Pearson, C. P., and Fitzharris, B. B.: Dependency of summer lake inflows and precipitation on spring SOI, J. Hydrol., 205, 66-80, 1998.

Purdie, J. M. and Bardsley, W. E.: Seasonal prediction of lake inflows and rainfall in a hydro-electricity catchment, Waitaki river, New Zealand, Int. J. Climatol., 30, 372-389, 2010.

Purdy, J. C. and Austin, G. L.: The role of synoptic cloud in orographic rainfall in the Southern Alps of New Zealand, Meteorol. Appl., 10, 355-365, 2003.

Salinger, J. M. and Mullan, A. B.: New Zealand climate: temperature and precipitation variations and their links with atmospheric circulation, Int. J. Climatol., 19, 1049-1071, 1999. 